\title{
АВТОНОМНЫЕ БИОЛЮМИНЕСЦЕНТНЫЕ СИСТЕМЫ: ПЕРСПЕКТИВЫ ИСПОЛЬЗОВАНИЯ В ИМИДЖИНГЕ ЖИВЫХ ОРГАНИЗМОВ
}

\author{
3. М. Осипова ${ }^{1,2}$, А. С. Щеглов ${ }^{1,2}$, И. В. Ямпольский ${ }^{1,2}$ \\ ${ }^{1}$ Институт биоорганической химии имени М. М. Шемякина и Ю. А. Овчинникова РАН, Москва, Россия \\ 2 Российский национальный исследовательский медицинский университет имени Н. И. Пирогова, Москва, Россия \\ Биолюминесцентные системы все чаще применяют для разработки высокочувствительных оптических методов имиджинга in vivo. Однако при \\ использовании популярных систем необходимо инъекционно вводить дорогие и малостабильные синтетические субстраты (люциферины) перед \\ каждым анализом. Автономные системы бактерий и грибов, которые недавно стали доступны для работы с эукариотическими клетками, по нашему \\ мнению, могут развиться в полноценный инструмент для создания новых технологий биолюминесцентного имиджинга.
}

Ключевые слова: биолюминесценция, люцифераза, люциферин, биоимиджинг, биомедицинские исследования, автономная биолюминесценция Финансирование: исследование выполнено за счет гранта Российского научного фонда (проект №17-14-01169).

Благодарности: авторы признательны Центру высокоточного редактирования и генетических технологий для биомедицины (Москва) за помощь в проведении исследования.

Информация о вкладе авторов: З. М. Осипова, А. С. Щеглов - анализ литературы, написание статьи; И. В. Ямпольский — идея публикации, редактирование статьи.

$\triangle$ Для корреспонденции: Александр Сергеевич Щеглов

ул. Миклухо-Маклая, д. 16/10, г. Москва, 117997; jukart@mail.ru

Статья получена: 03.12.2019 Статья принята к печати: 12.12.2019 Опубликована онлайн: 19.12.2019

DOI: $10.24075 /$ vrgmu.2019.083

\section{AUTONOMOUS BIOLUMINESCENT SYSTEMS: PROSPECTS FOR USE IN THE IMAGING OF LIVING ORGANISMS}

\author{
Osipova ZM $\mathrm{M}^{1,2}$, Shcheglov AS ${ }^{1,2}$, Yampolsky IV ${ }^{1,2}$ \\ ${ }^{1}$ Shemyakin-Ovchinnikov Institute of Bioorganic Chemistry, Moscow, Russia \\ ${ }_{2}^{2}$ Pirogov Russian National Research Medical University, Moscow, Russia
}

\begin{abstract}
Bioluminescent systems are increasingly being used for the development of highly sensitive optical imaging techniques in vivo. However, it is necessary to inject expensive and unstable synthetic substrates (luciferins) before each analysis for most of the systems applied. Autonomous bacterial and fungal bioluminescent systems, that recently have become available for implementation in eukaryotic cells, in our opinion, may be developed into an effective tool in new technologies
\end{abstract} of bioluminescent imaging.

Keywords: bioluminescence, luciferase, luciferin, bioimaging, biomedical research, autonomous bioluminescence

Funding: the study was supported by the Russian Science Foundation (Grant №17-14-01169).

Acknowledgements: we thank to the Center for Precision Genome Editing and Genetic Technologies for Biomedicine (Moscow) for the genetic research methods. Author contribution: Osipova ZM, Shcheglov AS — literature analysis, article authoring; Yampolsky IV — study planning, manuscript editing.

$\triangle$ Correspondence should be addressed: Alexander S. Shcheglov

Miklukho-Maklaya, 16/10, Moscow, 117997; jukart@mail.ru

Received: 03.12.2019 Accepted: 12.12.2019 Published online: 19.12.2019

DOI: $10.24075 /$ brsmu.2019.083

Оптический имиджинг in vivo все чаще используют в качестве метода визуализации в современных биомедицинских исследованиях $[1,2]$. В ходе биоимиджинга происходит неинвазивное изучение животных объектов, в которых свет испускается в результате окисления молекулы люциферина (химическая реакция, катализируемая белком люциферазой), либо в ответ на возбуждение флуоресцентного белка светом из внешнего источника. Наиболее популярными на сегодняшний день оптическими репортерными белками являются флуоресцентные (GFP и подобные ему варианты разных цветов), а также биолюминесцентные из насекомых (FLuc) и морских организмов (RLuc, GLuc). Область применения биолюминесцентного и флуоресцентного имиджинга на их основе в медицине чрезвычайно обширна и включает (но не ограничивается) изучением функций генов, белокбелковых взаимодействий, развития патогенных процессов и онкогенеза, разработкой лекарственных препаратов и т. д. как на уровне отдельных клеток и тканей, так и у лабораторных животных в режиме реального времени [3].

Среди бесспорных достоинств существующих технологий флуоресцентного имиджинга — огромное разнообразие доступных белков всех спектральных оттенков, а также большой функциональный набор инструментов на их основе (в том числе фотоактивируемые, фотопереключаемые белки, сенсоры) [4]. Тем не менее при использовании флуоресцентных белков необходимо наличие внешнего излучения, в результате чего чувствительность методов снижается из-за помех автофлуоресценции, фототоксичности и наличия ненулевого фонового сигнала. Получение изображения высокого разрешения in vivo обычно сопровождается сложной инвазивной процедурой [5]. Биолюминесцентные системы лишены таких недостатков и поэтому успешно конкурируют с флуоресцентными белками. Для биолюминесцентного имиджинга быстро стал доступен уровень разрешения вплоть до единичной клетки внутри 
живого организма. Однако возможная токсичность, низкая стабильность и высокая стоимость синтетических люциферинов (субстратов биолюминесценции), которые необходимо инъекционно вводить в организм перед каждым анализом, усложняют проведение биолюминесцентного имиджинга.

Применение автономных люминесцентных систем, для которых биосинтез люциферина может быть воспроизведен методами генной инженерии в клетках исследуемого организма, может стать полноправной альтернативой существующим технологиям биоимиджинга in vivo. К сожалению, среди тысяч ( 103) светящихся видов и около $40\left(\sim 10^{2}\right)$ различных механизмов свечения на данный момент известны структуры лишь 10 люциферинов (светящихся субстратов) и 7 семейств генов люцифераз $\left(\sim 10^{1}\right)$ [6, 7], а полный путь биосинтеза люциферина определен только для бактериальной [3] и, с недавнего времени, для грибной [8] биолюминесцентных систем. Есть сведения о том, что D-люцисрерин светляка в организме насекомых синтезируется из п-бензохинона и L-цистеина [9], однако соответствующие этим процессам белки пока не выделены. Белок LRE, регенерирующий D-люциферин из оксилюциферина $[10,11]$, не может стать полноценной заменой биосинтезу люминесцентного субстрата из распространенных метаболитов. Таким образом, на данный момент реальными кандидатами для создания новых автономных методов визуализации являются только две люминесцентные системы.

\section{Бактериальная биолюминесценция: от прокариот к эукариотам}

Биолюминесцентные бактерии - это самые распространенные светящиеся организмы; встречаются они в море и на суше. Биолюминесценция бактерий хорошо изучена: за их свечение отвечает кассета из пяти генов IUхCDABE. LUXAB кодирует гетеродимерную бактериальную люциферазу, luxC, luxD и luxE — три белка (редуктазу, трансферазу и синтазу), осуществляющие синтез субстрата (додеканаля) для реакции биолюминесценции (рис. 1А). Также дополнительно в кассету может быть включен ген frp, кодирующий флавинредуктазу, которая отвечает за синтез фрлавинмононуклеотида $\mathrm{FMNH}_{2}$, необходимого компонента реакции люминесценции [12]. Таким образом, бактериальная биолюминесцентная система может быть полностью перенесена в новый организм, который будет светиться без добавления люциферина извне. Из недостатков этой системы необходимо отметить зависимость от наличия $\mathrm{FMNH}_{2}$ и жирных альдегидов, невысокую яркость, и, самое главное, синий цвет люминесценции (490 нм), неудобный для имиджинга глубоких тканей in vivo.

Гетерологическая экспрессия генов автономной бактериальной люминесцентной системы была быстро и успешно реализована в прокариотических клетках [13], однако принципиальной сложностью для ее переноса в клетки эукариот стали большой размер оперона, его мультигенная организация и токсичность системы для организма-хозяина (вследствие цитотоксичности додеканаля). Для решения этой задачи появилась необходимость в проведении масштабной перестройки оперона.

Первым успехом на пути переноса автономной бактериальной люминесценции в эукариоты стало получение трансгенных светящихся дрожжей Saccharomyces cerevisiae [14]. Повышение эффективности экспрессии было достигнуто путем оптимизации кодонов и добавления линкерных участков. Немаловажным стал переход от люциферазы морских бактерий Vibrio harveyi к термостабильной люциферазе наземного вида Photorhabdus luminescens, сохраняющей активность при $37^{\circ} \mathrm{C}$. Тем не менее свечение было неярким и нестабильным. Первые удачные адаптация и оптимизация генов только бактериальной люциферазы ІихАВ для клеток НЕК293 были реализованы спустя 2 года [15]. Наконец, в 2010 г. было описано первое применение автономной бактериальной люминесценции в клетках млекопитающих для биоимиджинга in vivo с чувствительностью порядка 20000 клеток [16]. Параллельно были получены первые растения, светящиеся автономно [17].

Несмотря на проделанную работу по дальнейшей оптимизации и сокращению оперона для применения в клетках млекопитающих (например, [18]), существует ограниченное количество примеров применения бактериальной биолюминесценции для биоимиджинга эукариот [19-21] вследствие ее невысокой яркости относительно неавтономных систем, например D-люцисеринзависимых. Недавно благодаря дополнительным изменениям в опероне и использованию индивидуальных плазмид для настройки экспрессии генов в оптимальном соотношении удалось разработать новую бактериальную систему "CO LuX», яркость которой для одноклеточного имиджинга клеток НЕК293 сравнима с таковой для люциферазы FLuc [22, 23]. Невысокая концентрация длинноцепочечного альдегида не приводит $\mathrm{k}$ неблагоприятным токсическим эффектам. Единственным заметным эффектом стало уменьшение концентрации NADPH в светящихся клетках (вследствие повышенного расхода в ходе реакции биолюминесценции). Также появился первый пример автономного биоимиджинга на основе пары lUхAB и желтого флуоресцентного белка YРЕТ [24].

\section{Автономная биолюминесценция грибов: альтернатива бактериям}

Изучение светящихся грибов имеет многовековую историю, однако впервые структура люцифрерина грибов 3-гидроксигиспидина была установлена в 2015 г. [25], а в 2018 г. была описана люцифераза грибов и полный цикл биосинтеза люциферина из распространенного вторичного метаболита растений — кофейной кислоты и сразу же показан пример применения данной системы для создания автономно светящихся дрожжей [8] (рис. 1Б).

В основе люминесценции грибов лежат гены hisps, h3h, luz (люцифераза) и cph. Hisps, h3h кодируют белки, которые последовательно собирают гиспидин из кофейной кислоты (гиспидинсинтаза) и люциферин (3-гидроксигиспидин) соответственно. Luz кодирует люциферазу, а cph - белок, перерабатывающий продукт окисления люциферина (оксилюцисеерин) обратно в кофейную кислоту. Недавно было показано, что экспрессии лишь трех генов hisps, h3h и luz в растениях Nicotiana tabacum достаточно для создания ярких автономно светящихся растений [26, 27]. В отличие от бактериальной люминесцентной системы, здесь не требуется серьезной оптимизации кодонного состава генов для получения трансгенных растений, поскольку генетический материал изначально берется из эукариот и новый биосинтетический цикл хорошо встраивается в метаболизм организма-хозяина.

Однако первый пример получения автономно светящихся клеток млекопитающих НЕК293Т на 
A

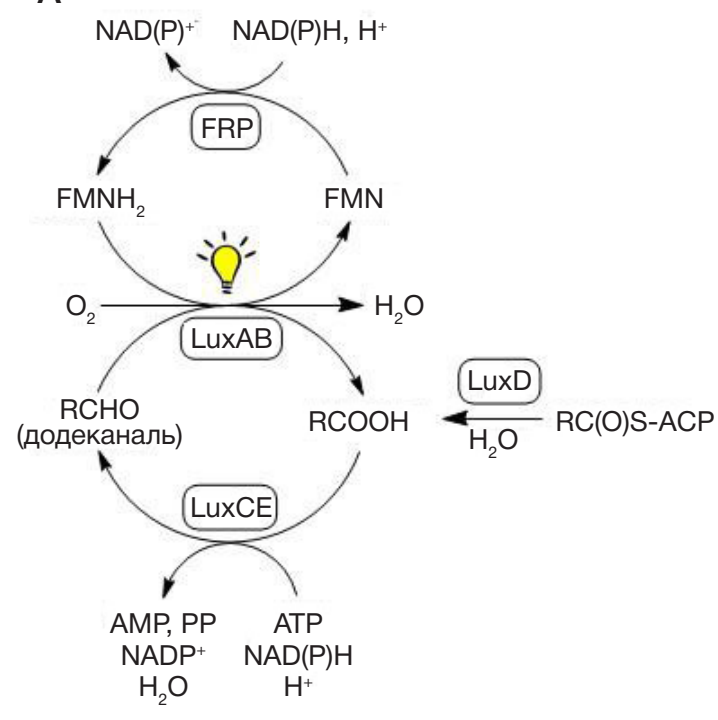

Б

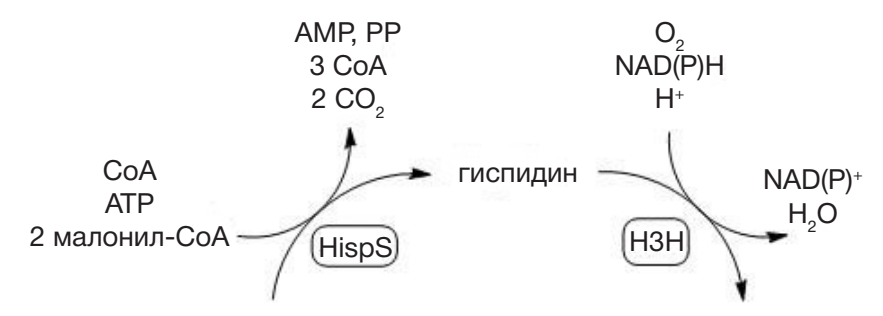

3-гидроксигиспидин (люциферин) кофейная пировиноградная кислота

Рис. 1. Биохимические циклы автономной биолюминесценции бактерий (А) и грибов (Б)

основе генов биолюминесценции грибов потребовал использования смеси уже восьми плазмид [26]. Полученные клетки светились нестабильно и не очень ярко, что указывает на очевидную необходимость оптимизации применяемых генетических конструкций для получения более ярких вариантов. Суммарная длина используемых на данный момент кодирующих последовательностей бактериальной системы биолюминесценции составляет 6,2 тыс. пар оснований (т.п.о.), тогда как для последовательностей грибной системы это значение составляет около 12,8 т.п.о., но оно может быть сокращено до 9,6 т.п.о. в случае использования альтернативных ферментов. В то же время существенным отличием автономной биолюминесценции грибов является максимум свечения в области 540 нм (желтый), что делает эту систему более перспективной для применения в биоимиджинге in vivo.

\section{ВЫВОДЫ}

Количество инструментов для оптического имиджинга в медицинских исследованиях постоянно увеличивается. По нашему мнению, более чувствительный in vivo биолюминесцентный имиджинг в будущем может составить конкуренцию устоявшимся флуоресцентным технологиям. Активно изучаемые в данный момент системы автономной биолюминесценции на основе кассет генов бактерий или грибов способны встать в один ряд с существующими.

\section{Литература}

1. Kiessling F, Pichler BJ, Hauff P, editors. Small animal imaging: Basics and practical guide. 2nd ed. Cham: Springer International Publishing AG, 2017.

2. Kubala E, Menzel MI, Feuerecker B, Glaser SJ, Schwaiger M. Molecular Imaging. In: Canales A, editor. Biophysical techniques in drug discovery. London: Royal Society of Chemistry, 2017; p. 277-306.

3. Kaskova ZM, Tsarkova AS, Yampolsky IV. 1001 lights: luciferins, luciferases, their mechanisms of action and applications in chemical analysis, biology and medicine. Chem Soc Rev. 2016; 45 (21): 6048-77.

4. Specht EA, Braselmann E, Palmer AE. A critical and comparative review of fluorescent tools for live-cell imaging. Annu Rev Physiol. 2017; (79): 93-117.

5. Yeh HW, Ai HW. Development and applications of bioluminescent and chemiluminescent reporters and biosensors. Annu Rev Anal Chem. 2019; (12): 129-50.

6. Shimomura O, Yampolsky I. Back matter. In: Shimomura O, Yampolsky I, editors. Bioluminescence: Chemical principles and methods. 3rd ed. Singapore: World Scientific Co. Pte. Ltd., 2019; p. 381-522.

7. Kotlobay AA, Dubinnyi MA, Purtov KV, Guglya EB, Rodionova NS, et al. Bioluminescence chemistry of fireworm Odontosyllis. Proc Natl Acad Sci USA. 2019; 116 (38): 18911-6.

8. Kotlobay AA, Sarkisyan KS, Mokrushina YA, Marcet-Houben M, Serebrovskaya EO, et al. Genetically encodable bioluminescent system from fungi. Proc Natl Acad Sci USA. 2018; 115 (50): 12728-32.
9. Kanie S, Nakai R, Ojika M, Oba Y. 2-S-cysteinylhydroquinone is an intermediate for the firefly luciferin biosynthesis that occurs in the pupal stage of the japanese firefly, Luciola lateralis. Bioorg Chem. 2018; (80): 223-9.

10. Gomi K, Kajiyama N. Oxyluciferin, a luminescence product of firefly luciferase, is enzymatically regenerated into luciferin. J Biol Chem. 2001; 276 (39): 36508-13.

11. Cheng YY, Liu YJ. Luciferin regeneration in firefly bioluminescence via proton transfer facilitated hydrolysis, condensation and chiral inversion. Chem Phys Chem. 2019; (20): 1719-27.

12. Tu SC. Activity coupling and complex formation between bacterial luciferase and flavin reductases. Photochem Photobiol Sci. 2008; 7 (2): 183-8.

13. Close DM, Xu T, Sayler GS, Ripp S. In vivo bioluminescent imaging (BLI): noninvasive visualization and interrogation of biological processes in living animals. Sensors. 2011; 11 (1): 180-206.

14. Gupta RK, Patterson SS, Ripp S, Simpson ML, Sayler GS. Expression of the Photorhabdus luminescens lux genes (luxA, B, C, D, and E) in Saccharomyces cerevisiae. FEMS Yeast Res. 2003; 4 (3): 305-13.

15. Patterson SS, Dionisi HM, Gupta RK, Sayler GS. Codon optimization of bacterial luciferase (lux) for expression in mammalian cells. J Ind Microbiol Biotechnol. 2005; 32 (3): 115-23.

16. Close DM, Patterson SS, Ripp S, Baek SJ, Sanseverino J, et al. Autonomous bioluminescent expression of the bacterial luciferase gene cassette (lux) in a mammalian cell line. PloS one. 2010; 5 (8): e12441. 
17. Krichevsky A, Meyers B, Vainstein A, Maliga P, Citovsky V. Autoluminescent plants. PloS one. 2010; 5 (11): e15461.

18. Xu T, Ripp S, Sayler GS, Close DM. Expression of a humanized viral 2A-mediated lux operon efficiently generates autonomous bioluminescence in human cells. PLoS One. 2014; 9 (5): e96347.

19. Class B, Thorne N, Aguisanda F, Southall N, McKew JC, et al. Highthroughput viability assay using an autonomously bioluminescent cell line with a bacterial lux reporter. J Lab Autom. 2015; 20 (2): 164-74.

20. Xu T, Young A, Marr E, Sayler G, Ripp S, et al. A rapid and reagent-free bioassay for the detection of dioxin-like compounds and other aryl hydrocarbon receptor (AhR) agonists using autobioluminescent yeast. Anal Bioanal Chem. 2018; 410 (4): 1247-56.

21. Xu T, Kirkpatrick A, Toperzer J, Ripp S, Close D. Improving estrogenic compound screening efficiency by using selfmodulating, continuously bioluminescent human cell bioreporters expressing a synthetic luciferase. Toxicol Sci. 2019; 168 (2): 551-60.

\section{References}

1. Kiessling F, Pichler BJ, Hauff P, editors. Small animal imaging: Basics and practical guide. 2nd ed. Cham: Springer International Publishing AG, 2017.

2. Kubala E, Menzel MI, Feuerecker B, Glaser SJ, Schwaiger M. Molecular Imaging. In: Canales A, editor. Biophysical techniques in drug discovery. London: Royal Society of Chemistry, 2017; p. 277-306.

3. Kaskova ZM, Tsarkova AS, Yampolsky IV. 1001 lights: luciferins, luciferases, their mechanisms of action and applications in chemical analysis, biology and medicine. Chem Soc Rev. 2016; 45 (21): 6048-77.

4. Specht EA, Braselmann E, Palmer AE. A critical and comparative review of fluorescent tools for live-cell imaging. Annu Rev Physiol. 2017; (79): 93-117.

5. Yeh HW, Ai HW. Development and applications of bioluminescent and chemiluminescent reporters and biosensors. Annu Rev Anal Chem. 2019; (12): 129-50.

6. Shimomura O, Yampolsky I. Back matter. In: Shimomura O, Yampolsky I, editors. Bioluminescence: Chemical principles and methods. 3rd ed. Singapore: World Scientific Co. Pte. Ltd., 2019; p. 381-522.

7. Kotlobay AA, Dubinnyi MA, Purtov KV, Guglya EB, Rodionova NS, et al. Bioluminescence chemistry of fireworm Odontosyllis. Proc Natl Acad Sci USA. 2019; 116 (38): 18911-6.

8. Kotlobay AA, Sarkisyan KS, Mokrushina YA, Marcet-Houben M, Serebrovskaya EO, et al. Genetically encodable bioluminescent system from fungi. Proc Natl Acad Sci USA. 2018; 115 (50) 12728-32.

9. Kanie S, Nakai R, Ojika M, Oba Y. 2-S-cysteinylhydroquinone is an intermediate for the firefly luciferin biosynthesis that occurs in the pupal stage of the japanese firefly, Luciola lateralis. Bioorg Chem. 2018; (80): 223-9.

10. Gomi K, Kajiyama N. Oxyluciferin, a luminescence product of firefly luciferase, is enzymatically regenerated into luciferin. J Biol Chem. 2001; 276 (39): 36508-13.

11. Cheng YY, Liu YJ. Luciferin regeneration in firefly bioluminescence via proton transfer facilitated hydrolysis, condensation and chiral inversion. Chem Phys Chem. 2019; (20): 1719-27.

12. Tu SC. Activity coupling and complex formation between bacterial luciferase and flavin reductases. Photochem Photobiol Sci. 2008; 7 (2): 183-8

13. Close DM, Xu T, Sayler GS, Ripp S. In vivo bioluminescent imaging (BLI): noninvasive visualization and interrogation of biological processes in living animals. Sensors. 2011; 11 (1): 180-206.

14. Gupta RK, Patterson SS, Ripp S, Simpson ML, Sayler GS Expression of the Photorhabdus luminescens lux genes (luxA,
22. Gregor C, Gwosch KC, Sahl SJ, Hell SW. Strongly enhanced bacterial bioluminescence with the ilux operon for single-cell imaging. Proc Natl Acad Sci USA. 2018; 115 (5): 962-7.

23. Gregor C, Pape JK, Gwosch KC, Gilat T, Sahl SJ, et al. Autonomous bioluminescence imaging of single mammalian cells with the bacterial bioluminescence system. bioRxiv. 2019: 798108 .

24. Srinivasan P, Griffin NM, Joshi P, Thakur DP, Nguyen-Le A, et al. An Autonomous Molecular Bioluminescent Reporter (AMBER) for voltage imaging in freely moving animals. bioRxiv. 2019: 845198.

25. Purtov KV, Petushkov VN, Baranov MS, Mineev KS, Rodionova NS, et al. The chemical basis of fungal bioluminescence. Angew Chem Int Ed. 2015; 54 (28): 8124-8.

26. Mitiouchkina T, Mishin AS, Somermeyer LG, Markina NM, Chepurnyh TV, et al. Plants with self-sustained luminescence. bioRxiv. 2019: 809376

27. Khakhar A, Starker C, Chamness J, Lee N, Stokke S. Building customizable auto-luminescent luciferase-based reporters in plants. bioRxiv. 2019: 809533 .

B, C, D, and E) in Saccharomyces cerevisiae. FEMS Yeast Res. 2003; 4 (3): 305-13.

15. Patterson SS, Dionisi HM, Gupta RK, Sayler GS. Codon optimization of bacterial luciferase (lux) for expression in mammalian cells. J Ind Microbiol Biotechnol. 2005; 32 (3): 115-23.

16. Close DM, Patterson SS, Ripp S, Baek SJ, Sanseverino J, et al. Autonomous bioluminescent expression of the bacterial luciferase gene cassette (lux) in a mammalian cell line. PloS one. 2010; 5 (8): e12441.

17. Krichevsky A, Meyers B, Vainstein A, Maliga P, Citovsky V. Autoluminescent plants. PloS one. 2010; 5 (11): e15461.

18. Xu T, Ripp S, Sayler GS, Close DM. Expression of a humanized viral 2A-mediated lux operon efficiently generates autonomous bioluminescence in human cells. PLoS One. 2014; 9 (5): e96347.

19. Class B, Thorne N, Aguisanda F, Southall N, McKew JC, et al. Highthroughput viability assay using an autonomously bioluminescent cell line with a bacterial lux reporter. J Lab Autom. 2015; 20 (2): 164-74.

20. Xu T, Young A, Marr E, Sayler G, Ripp S, et al. A rapid and reagent-free bioassay for the detection of dioxin-like compounds and other aryl hydrocarbon receptor (AhR) agonists using autobioluminescent yeast. Anal Bioanal Chem. 2018; 410 (4): 1247-56

21. Xu T, Kirkpatrick A, Toperzer J, Ripp S, Close D. Improving estrogenic compound screening efficiency by using selfmodulating, continuously bioluminescent human cell bioreporters expressing a synthetic luciferase. Toxicol Sci. 2019; 168 (2): 551-60.

22. Gregor C, Gwosch KC, Sahl SJ, Hell SW. Strongly enhanced bacterial bioluminescence with the ilux operon for single-cell imaging. Proc Natl Acad Sci USA. 2018; 115 (5): 962-7.

23. Gregor C, Pape JK, Gwosch KC, Gilat T, Sahl SJ, et al. Autonomous bioluminescence imaging of single mammalian cells with the bacterial bioluminescence system. bioRxiv. 2019: 798108 .

24. Srinivasan P, Griffin NM, Joshi P, Thakur DP, Nguyen-Le A, et al. An Autonomous Molecular Bioluminescent Reporter (AMBER) for voltage imaging in freely moving animals. bioRxiv. 2019: 845198.

25. Purtov KV, Petushkov VN, Baranov MS, Mineev KS, Rodionova NS, et al. The chemical basis of fungal bioluminescence. Angew Chem Int Ed. 2015; 54 (28): 8124-8.

26. Mitiouchkina T, Mishin AS, Somermeyer LG, Markina NM, Chepurnyh TV, et al. Plants with self-sustained luminescence. bioRxiv. 2019: 809376.

27. Khakhar A, Starker C, Chamness J, Lee N, Stokke S. Building customizable auto-luminescent luciferase-based reporters in plants. bioRxiv. 2019: 809533 . 